candidate was selected, where only the English candidate was selected, and where both were selected. The Asian candidate was never shortlisted unless the English candidate was also shortlisted. The outcome was different in six pairs $\left(\chi^{2}=4 \cdot 17, p=0.03, d f=1\right)$.

\section{Comment}

We originally planned a survey covering approximately 100 posts and all hospital specialties; unfortunately we were arrested by the fraud squad and charged with making fraudulent applications. Although not prosecuted, we were advised against continuing the work. Nevertheless, our results are important and suggest that discrimination does take place against ethnic minorities, apparently at shortlisting. English applicants were twice as likely to be selected, and this difference would probably have been greater had we carried out the full study and been able to include posts in teaching hospitals. Doctors from ethnic minorities predominate in at least two of our chosen specialties (psychiatry and geriatric medicine)-reflecting these specialties' comparative unpopularity ${ }^{3}$-and the proportion of such doctors is much greater in district general hospitals than in teaching hospitals. ${ }^{2}$ It is remarkable therefore that despite these two biases we still found a twofold difference.

Mechanisms could easily be incorporated to reduce the chance of name and ethnicity determining the likelihood of being shortlisted, as well as to monitor discrimination. As a start, we suggest that all application forms for medical posts should be standardised so that information identifying ethnic origin can be removed by the personnel department-for example, on a detachable front sheet. Ethnic monitoring should also be standard personnel practice so that all districts and regions can monitor whether equal opportunity policies are actually being implemented.

The research was commissioned and supported by the Medical Practitioners Union, 50 Southwark Street, London SE1 5UN.

1 McKeigue PM, Richards JDM, Richards P. Effects of discrimination by sex and race on the early careers of British medical undergraduates durin 1981-7. BMF 1990;301:961-4

2 Anwar M, Ali A. Overseas doctors: experience and expectations. London: Commission for Racial Equality, 1987.

3 Community Relations Commission. Doctors from overseas: a case for consultation. London: CRC, 1976

(Accepted 21 fanuary 1993)

\title{
Communication between general practitioners and child psychiatrists
}

\author{
Peter L Cornwall
}

Department of Child and Family Psychiatry, Sunderland District General Hospital, Sunderland SR4 7TP

Peter L Cornwall, registrar

$B M F$ 1993;306:692-3
Previous studies have examined the content of referral letters from general practitioners to consultants as well as the requirements of consultants. ${ }^{1-4}$ Child psychiatrists have a special interest in information about the child's family, as often the whole family will attend for assessment. This study aimed to review the content of referral letters from general practitioners to a child psychiatry department and to discover whether general practitioners and psychiatrists hold different views on the information that should be included in a referral letter.

\section{Methods and results}

From a consecutive series of 50 referral letters sent by general practitioners in Sunderland to the local department of child psychiatry, 15 items of information were identified that could account for all the information contained in the letters. The frequency with which each item appeared in the letters was recorded. Postal

Information contained in referral letters from general practitioners of department of child psychiatry

\begin{tabular}{lcc}
\hline & $\begin{array}{c}\text { No (\%) of } \\
\text { sample letters } \\
(\mathrm{n}=50)\end{array}$ & $\begin{array}{c}\text { Agreement between } \\
\text { GPs and psychiatrists } \\
\text { about importance of } \\
\text { items }\left(\chi^{2}, \mathrm{df}=3\right)\end{array}$ \\
Item & $46(92)$ & $3 \cdot 5$ \\
Presenting symptoms and problems & $20(40)$ & $10^{\star} \cdot 9^{\star}$ \\
History of presenting problems & $19(38)$ & $2 \cdot 4$ \\
Composition of the family & $18(36)$ & $3 \cdot 2$ \\
Past medical and psychiatric history & $12(24)$ & $7 \cdot 6$ \\
Personal history including development and schooling & $11(22)$ & $15 \cdot 3^{\star \star}$ \\
Assessment of family dynamics and relationships & $9(18)$ & $8 \cdot 9^{\star}$ \\
Attitude of the family to referral & $9(18)$ & $5 \cdot 4$ \\
Provisional diagnosis & $9(18)$ & $0 \cdot 5$ \\
Drug history including recent treatment & $8(16)$ & $2 \cdot 9$ \\
Reason for and urgency of referral & $8(16)$ & $16 \cdot 0^{\star \star}$ \\
Whether other agencies are involved & $5(10)$ & $4 \cdot 9$ \\
Family medical and psychiatric history & $4(8)$ & $16 \cdot 0^{\star \star}$ \\
Assessment of mental state of child & $4(8)$ & $3 \cdot 0$ \\
Physical assessment of the child & $4(8)$ & $2 \cdot 3$ \\
Information and advice given to the family & & \\
\hline
\end{tabular}

${ }^{\star} \mathrm{p}<0.05,{ }^{\star \star} \mathrm{p}<0.01$. questionnaires were then used to seek the views of local general practitioners and the child psychiatrists working in the Northern region. They were required to assess the importance of the 15 categories of information on a four point scale (categories of essential, desirable, doubtful, and irrelevant). They were also asked their views on the quality of referral letters in general.

Questionnaires were returned by $93(63 \%)$ general practitioners and $26(90 \%)$ psychiatrists. The table shows the frequency with which the 15 items of information occurred in the letters and the comparison of the importance given to the different items by the psychiatrists and the general practitioners.

The reason most often mentioned by general practitioners for poor quality letters was lack of time. A few replies contained the comment that families were sometimes reluctant to reveal information to their doctor. The main complaint from psychiatrists was that referral letters were too brief, with key information (particularly the attitude of the family to the referral and to involvement of other agencies) often absent.

\section{Comment}

Although the categorisation of information from referral letters is somewhat arbitrary, the study has the advantage that the items which the two groups of doctors were asked to assess were taken from a sample of actual letters. The study, moreover, replicates the finding by Kentish $e t$ al that the only item of information which is found consistently in referral letters is a description of the presenting symptoms. ${ }^{3}$ There was some consensus about the relative importance of certain items of information that a referral letter should include, but psychiatrists rated two key items of information of more importance: the attitude of the family to referral and whether other agencies are involved.

The attitude of the family has implications for the style of initial assessment carried out by the psychiatrist; if the psychiatrist realises from the outset that other agencies are involved then consent of the family for reports may be obtained at an early stage. Many general practitioners seem unaware of the importance for the psychiatrist of possessing this information before the family attends for the first appointment. It also seems that psychiatrists are 
sometimes unaware of the difficulties that general practitioners may face in obtaining the information required.

Marinker et al have recommended the development of protocols for referral between general practitioners and consultants. ${ }^{5}$ Some departments of child psychiatry now use standardised referral forms with specific questions on the attitude of the family to referral and involvement of other agencies. This study has shown that child psychiatrists have some special requirements for referral letters, but they are unlikely to obtain the desired information unless they educate general practitioners.
I am indebted to Maurice Place for his support and advice at every stage of this project.

1 Williams P, Wallace BB. General practitioners and psychiatrists-do they communicate? BMf 1974;i:505-7.

2 Pullen IM, Yellowlees AJ. Is communication improving between general practitioners and psychiatrists? $B M \mathcal{F} 1985 ; 290: 31-3$.

3 Kentish R, Jenkins P, Lask B. Study of written communication between general practitioners and departments of child psychiatry. $\exists R$ Coll Gen Pract 1987;37:162-3.

4 Newton J, Eccles M, Hutchinson A. Communication between general practitioners and consultants: what should their letter contain? $B M 7$ 1992;304: $821-4$

5 Marinker $M$, Wilkin D, Metcalfe DH. Referral to hospital: can we do better? $B M F$ 1988;297:461-4.

(Accepted 21 fanuary 1993)

\section{Drug misusers in Lothian: changes in injecting habits 1988-90}

\section{Shay Griffin, Andy Peters, Margaret Reid}

Community Drug Problem Service, Royal Edinburgh Hospital, Edinburgh EH10 5BT

Shay Griffin, clinical assistant Andy Peters, chartered clinical psychologist Margaret Reid, research psychologist

\section{Correspondence to:}

Dr Griffin.

BMF 1993;306:693
Of $941 \mathrm{HIV}$ seropositive cases reported in Edinburgh up to September 1992, $515(55 \%)$ were associated with injecting drug misuse. ${ }^{1} \mathrm{HIV}$ and drug targeted services in the region have concentrated on a "harm reduction" approach, one aspect of which is to encourage injectors at least to use a safe injecting technique but preferably to switch to oral use. The aim of this study was to verify a strong clinical impression that injecting drug misuse in Lothian has recently diminished.

\section{Subjects, methods, and results}

The community drug problem service, the setting for this study, has been described. ${ }^{2}$ The data presented were drawn from detailed clinical interview of new patients at the point of initial assessment. Fifty consecutive referrals in 1988 were compared with 50 consecutive referrals in 1990 with respect to demographic characteristics and patterns of drug misuse. These included injecting frequency (past and recent), prescription status at assessment, drugs reportedly used, and syringe sharing. Injecting frequency was defined as never (no injecting), occasional (averaging fewer than two injecting episodes a week), and frequent (averaging two or more episodes a week). "Recent" injecting refers to the six months before assessment. "Past" injecting refers to the injecting career before that period.

The two samples did not differ in sex, age, employment status, proportion with a regular partner, source of referral, age at first drug misuse (excluding cannabis, solvents, and alcohol), or age at first injecting (among injectors).

The table shows significant differences between the two years in past injecting frequency $\left(\chi^{2}=19 \cdot 9, \mathrm{df}=2\right.$;

Comparison of 1988 and 1990 samples for past injecting frequency (whole samples), recent injecting frequency among past injectors only, and frequency of recent injecting among frequent past injector

\begin{tabular}{|c|c|c|c|c|c|c|}
\hline \multirow[b]{3}{*}{ Injecting frequency ${ }^{\star}$} & \multirow{2}{*}{\multicolumn{2}{|c|}{ Past injectingt }} & \multicolumn{4}{|c|}{ Recent injecting $\ddagger$} \\
\hline & & & \multicolumn{2}{|c|}{$\begin{array}{l}\text { Past intravenous } \\
\text { drug misusers }\end{array}$} & \multicolumn{2}{|c|}{$\begin{array}{l}\text { Frequent past } \\
\text { intravenous } \\
\text { drug misusers }\end{array}$} \\
\hline & 1988 & 1990 & 1988 & 1990 & 1988 & 1990 \\
\hline No (\%) never & $2(4)$ & $13(27)$ & $6(13)$ & $17(50)$ & $6(13)$ & $12(48)$ \\
\hline No $(\%)$ occasional & $1(2)$ & $9(18)$ & $6(13)$ & $11(32)$ & $6(13)$ & $8(3)$ \\
\hline No $(\%)$ frequent & $47(94)$ & $27(55)$ & $36(75)$ & $6(18)$ & $35(74)$ & $5(20)$ \\
\hline $\mathrm{p}$ Value & \multicolumn{2}{|c|}{$<0.0001$} & \multicolumn{2}{|c|}{$<0.0001$} & \multicolumn{2}{|c|}{$<0.0001$} \\
\hline
\end{tabular}

* See text for definitions.

tRefers to injecting history more than six months before assessment.

$\ddagger$ Refers to injecting history in six months before assessment. $\mathrm{p}<0.0001)$, recent injecting frequency $\left(\chi^{2}=26 \cdot 6\right.$, $\mathrm{df}=2 ; \mathrm{p}<0.0001)$, and recent injecting frequency among frequent past injectors $\left(\chi^{2}=19 \cdot 9, \mathrm{df}=2\right.$; $p<0.0001)$. This last finding excludes the possibility that the preponderance of frequent past injectors in 1988 could account for differences between 1988 and 1990 in recent injecting frequency.

Among recent injectors $37 \%$ (13/35) had recently shared syringes in 1988 compared with $20 \%(3 / 15)$ in 1990. This difference was not significant. Among opioid misusers $51 \%(24 / 47)$ in 1988 and $70 \%(30 / 43)$ in 1990 were receiving prescribed opioids before assessment. Among benzodiazepine misusers 70\% (23/33) in 1988 and $59 \%(23 / 39)$ in 1990 were being prescribed benzodiazepines before assessment. These differences were not significant. (Some patients reported being prescribed both drug types.)

Of the drugs in use within one month before assessment, injectable opioids such as Temgesic (buprenorphine) were significantly more commonly reported in 1988 than in 1990. Dihydrocodeine (rather than methadone) was the non-injectable opioid most commonly reported in both years but was significantly more popular in 1990 than in 1988.

The 1988 and 1990 samples were combined to test for association between prescribing status before assessment and frequency of recent injecting. Receiving a benzodiazepine prescription was not associated with recent injecting frequency. However, being prescribed opioids before assessment was strongly associated with lower recent injecting frequency $\left(\chi^{2}=25 \cdot 7\right.$, $\mathrm{df}=2 ; \mathrm{p}<0.0001)$.

\section{Comment}

In this study sample sizes were small. Nevertheless, it is clear that something has happened in Lothian to diminish injecting prevalence among clinic attenders. Reported opioid misuse seems to reflect this trend. Being prescribed oral opioids before assessment was associated with less recent injecting but as levels of such prescribing were similar in the two samples this would not, as a "treatment effect," fully explain the differences found in recent injecting frequency. Availability of oral opioids on the "grey market" to drug users not receiving a prescription may be a factor. Other possible factors may include the influence of public and drug user targeted education and changes in attitude owing to drug users' personal experience of friends and relatives becoming ill and dying of HIV related conditions.

Study of an "out of treatment" group might disclose to what extent, if at all, the trends reported reflect behaviour change in the wider population of drug misusers in Lothian.

1 Communicable Diseases (Scotland) Unit, Ruchill Hospital, Glasgow. AIDS Weekly News Supplement 1992 Sep 30: No 272.

2 Greenwood J. Creating a new drug service in Edinburgh. BMF 1990;300:587-9.

(Accepted 7 January 1993) 